Manesh Patel frCAnaes, George Samsoon FrCAnaes, Atul Swami FrCAnaes, Barbara Morgan FRCAnaes

\title{
Posture and the spread of hyperbaric bupiva- caine in parturients using the combined spinal epidural technique
}

This study was undertaken to analyze the effect of posture on the spread of hyperbaric bupivacaine in pregnant women using a combined spinal extradural technique, and to assess the quality of analgesia provided by $10 \mathrm{mg}$ bupivacaine when using this technique. Fifty parturients undergoing elective Caesarean section under regional anaesthesia were randomly allocated to receive $2.0 \mathrm{ml}$ hyperbaric bupivacaine $0.5 \%$ in either the sitting or left lateral position. Spinal injection was performed with a 27 gauge, $120 \mathrm{~mm}$ long spinal needle using a single space combined spinal extradural technique. The onset time to analgesia at $T_{4}$ and grade 3 motor block was on average $7.7 \mathrm{~min}$ and 6.9 min respectively in the lateral group, compared with 10.8 $\min (P<0.05)$ and $9.4 \min (P<0.05)$ in the sitting group. Nine women in the sitting group and one woman $(P<0.05)$ in the lateral group required epidural supplementation. Hypotension occurred in $48 \%$ of the parturients in the lateral group and in $13 \%(P<0.05)$ of the parturients in the sitting group. Nausea was noted in $61 \%$ of the parturients in the lateral group and in $22 \%(P<0.05)$ of the parturients in the sitting group. There was no difference between the two groups in neonatal outcome. Overall, the position of the patient during induction of spinal anaesthesia does influence the rate of onset of analgesia and motor blockade. Injection of $10 \mathrm{mg}$ hyperbaric bupivacaine in the sitting position would not provide adequate analgesia for Caesarean section when using a single space combined spinal extradural technique.

\section{Key words}

ANAESTHESIA: obstetric;

ANAESTHETIC TECHNIQUES: epidural, spinal;

ANAESTHETICS, LOCAL: bupivacaine.

From the Department of Anaesthesia, Queen Charlotte's and Chelsea Hospital, Goldhawk Road, London.

Address correspondence to: Dr. Manesh Patel, Anaesthetic Department, Charing Cross Hospital, Fulham Palace Road, London, W6 8RF, United Kingdom.

Accepted for publication 28th June, 1993.
Cette étude vise à évaluer: 1) l'effet de la position sur la dispersion, chez la parturiente, de la buprvacaïne pendant une technique combinant la rachianesthésie à l'épidurale, 2) la qualité de l'anesthésie produite par bupivacaïne $10 \mathrm{mg}$ avec cette technique. Cinquante parturientes programmées pour césarienne sont réparties au hasard pour recevoir de la bupivacaïne hyperbare 0,5\% 2,0 $\mathrm{ml}$ en position latérale gauche (groupe latéral) ou assise (groupe assis). Linjection rachidienne est réalisée avec une aiguille $27 \mathrm{G}$ de $120 \mathrm{~mm}$ de longueur insérée dans l'espace choisi pour la technique combinée rachi-épidurale. La vitesse d'installation jusqu'à l'analgésie au niveau $T_{4}$ et le bloc moteur de grade 3 sont en moyenne de $7,7 \mathrm{~min}$ et $6,9 \mathrm{~min}$ respectivement dans le groupe latéral, comparativement à 10,8 $(P<0,05)$ et 9,4 min dans le groupe assis $(P<0,05)$. Neuf patientes du groupe assis et une seule $(P<0,05)$ du groupe latéral ont besoin d'un supplément épidural. De l'hypotension survient dans $48 \%$ du groupe latéral et dans $13 \%$ du groupe assis $(P<0,05)$. On retrouve de la nausée dans $61 \%$ du groupe latéral et dans $22 \%$ du groupe assis $(P<0,05)$. Létat du nouveau-né est identique dans les deux groupes. En général, la position de la parturiente pendant l'induction de la rachianesthésie a une influence sur la rapidité d'installation de l'analgésie et du bloc moteur. Linjection de bupivacaïne hyperbare $10 \mathrm{mg}$ en position assise ne produit pas une analgésie satisfaisante pour la césarienne quand on utilise la technique combinée rachi-épidurale administrée dans le même espace.

Subarachnoid anaesthesia is becoming increasingly popular in obstetric practice ${ }^{1}$ as it provides rapid onset and density of spinal block, combined with the ability to extend the block and provide postoperative analgesia with the extradural catheter. Russell investigated the effect of posture (right lateral versus left lateral) during and after induction of spinal anaesthesia, ${ }^{2,3}$ on the spread of isobaric bupivacaine in pregnant women. However, similar studies using hyperbaric bupivacaine have not been reported especially comparing the sitting with the left lateral 
position. It has also been suggested that $7.5-10 \mathrm{mg}$ bupivacaine is an inadequate dose for subarachnoid anaesthesia for Caesarean section. ${ }^{4,5}$ Thus, this study was undertaken to evaluate the effect of posture (sitting versus left lateral position) on the spread of hyperbaric bupivacaine when using the combined spinal extradural technique and to determine the quality of analgesia obtained for Caesarean section with a subarachnoid injection of $2.0 \mathrm{ml}$, hyperbaric bupivacaine $0.5 \%$.

\section{Methods}

Fifty healthy patients without maternal or fetal complications scheduled for elective primary or repeat Caesarean section under regional anaesthesia were selected for participation in the study. Informed consent was obtained in accordance with the protocol approved by the Ethical Committee. Patients were randomly allocated to receive spinal anaesthesia in either the sitting or the left lateral position using a combined spinal and extradural (CSE) technique. ${ }^{6,7}$

Each patient was premedicated with oral ranitidine 150 $\mathrm{mg}$ on the night before surgery, and ranitidine $150 \mathrm{mg}$ with metoclopramide $10 \mathrm{mg}$ po $90 \mathrm{~min}$ before operation. On arrival at the operating theatre, the patients were appropriately positioned, and monitoring of ECG, noninvasive arterial pressure and pulse oximetry was performed throughout the procedure. A 16 gauge intravenous cannula was inserted into a forearm vein and one litre Ringer's lactate was infused rapidly.

Using a midline approach, a 16 gauge Tuohy needle was introduced into the $\mathrm{L}_{2-3}$ space and the epidural space identified using loss of resistance to air or saline. a 12 $\mathrm{cm}, 27$ gauge Becton-Dickinson needle was threaded through an extradural needle. Free flow of cerebro-spinal fluid (CSF) was obtained before injection of local anaesthetic. Two millilitres hyperbaric bupivacaine $0.5 \%$ were then injected via the spinal needle over 30 seconds. When the injection was complete, the spinal needle was removed and the extradural catheter was inserted so that $3 \mathrm{~cm}$ remained in the extradural space. No injection was made through the catheter at this time. The patients were then placed supine with a $20^{\circ}$ right lateral tilt. Time taken from subarachnoid injection to supine position was also noted.

Arterial pressure and heart rate were recorded at twominute intervals following the subarachnoid injection, for the first $20 \mathrm{~min}$ and at five-minute intervals thereafter. Maternal hypotension (defined as a decrease in systolic arterial pressure $>30 \mathrm{mmHg}$ or $<100 \mathrm{mmHg}$ ) was avoided by administration of ephedrine infusion (ephedrine $60 \mathrm{mg}$ in Ringer's lactate solution one litre). If hypotension occurred despite this prophylaxis, it was treated
TABLE I Patient characteristics (mean (range or SD))

\begin{tabular}{lll}
\hline & $\begin{array}{l}\text { Sitting } \\
(n=24)\end{array}$ & $\begin{array}{l}\text { Lateral } \\
(n=24)\end{array}$ \\
\hline Age (yr) & $34.3(18-40)$ & $33.9(19-39)$ \\
Weight (kg) & $77.2(10.2)$ & $78.1(11.1)$ \\
Height (cm) & $165(7.7)$ & $166(8.1)$ \\
Gestation (wk) & $38(1.7)$ & $38(1.5)$ \\
\hline
\end{tabular}

with increments of ephedrine $3 \mathrm{mg}$ by $i v$ bolus administration.

Cutaneous analgesia levels were determined by loss of cold sensation to ethyl chloride at two-minute intervals. The time from injection of local anaesthetic to achieving bilateral analgesia to $T_{4}$ was defined as the onset time. Motor block was assessed by loss of leg power on a four point Bromage scale $(0-3),{ }^{8}$ and the time to reach grade 3 was noted $(0$, full flexion of knees and feet; 1 , just able to move knees; 2 , able to move feet only; and 3, unable to move feet and knees). These measurements were carried out by a second anaesthetist who was one of the authors.

If at six minutes sensory blockade had not reached $\mathrm{T}_{10}, 10 \mathrm{ml}$ plain bupivacaine $0.5 \%$ with $1: 200,000$ adrenaline were injected slowly through the extradural catheter.

The condition of the neonates was assessed by Apgar score at one and five minutes and by acid base sampling of cord blood at birth. The time from uterine incision to delivery of the infant was noted as the uterine incision to delivery time (U/D time).

The incidence and frequency of complications were noted and the efficacy of the sensory blockade was recorded by placing the patients in one of four categories: category A: no discomfort at all during the procedure; category B: mild discomfort but no systemic analgesia required; category $\mathrm{C}$ : pain that required analgesia (either via epidural or $i v$ route); and category $\mathrm{D}$ : general anaesthesia after commencement of surgery.

Statistical analysis was performed using an unpaired $\mathrm{t}$ test and chi-square tests as appropriate. $P<0.05$ was regarded as statistically significant.

\section{Results}

There was no difference between the two groups with regard to age, height, weight or gestational age (Table I). One patient from each group was withdrawn from the study due to failed subarachnoid block. One of the failures was due to loss of local anaesthetic from the syringe during injection and the other was due to needle displacement during injection. These patients had a Caesarean section performed under epidural anaesthesia.

Subarachnoid block characteristics are shown in Table 
TABLE II Subarachnoid block characteristics (mean (SD))

\begin{tabular}{|c|c|c|c|}
\hline & Sitting & Lateral & $P$ value \\
\hline Onset time to $T_{4}(\mathrm{~min})$ & $10.8(4.0)$ & $7.7(3.6)^{*}$ & $<0.05$ \\
\hline Onset of grade 3 motor block (min) & $9.4(3.1)$ & $6.9(2.4)^{*}$ & $<0.05$ \\
\hline $\begin{array}{l}\text { Analgesia }>T_{10} \text { at } 6 \mathrm{~min} \text { (no. of } \\
\text { patients) }\end{array}$ & 15 & $23^{*}$ & $<0.05$ \\
\hline $\begin{array}{l}\text { Epidural bupivacaine (no. of } \\
\text { patients) }\end{array}$ & 9 & $1^{*}$ & $<0.05$ \\
\hline Ephedrine & $27.2(12.4)$ & $31.4(8.9)$ & NS \\
\hline
\end{tabular}

*Significant difference between the two groups $(P<0.05)$.

II. Spinal injection in the lateral group produced faster onset of analgesia to $\mathrm{T}_{4}(P<0.05)$ and motor block to grade $3(P<0.05)$. More patients in the sitting group $(P<0.05)$ required epidural supplementation. The mean time to reach $T_{4}$ analgesia in the nine patients that required epidural supplementation was $13.7 \mathrm{sec}( \pm 4.3 \mathrm{SD})$. The time taken from subarachnoid injection to the supine position was $91 \mathrm{sec}$ (range 51-126 sec) in the sitting group and $47 \mathrm{sec}$ (range $38-57 \mathrm{sec}$ ) in the lateral group. ( $P$ $=\mathrm{NS}$ ).

None of the patients required general anaesthesia for surgery. Eighty percent (37/46) of the patients felt no pain at all, but $4 \%(2 / 46)$ required supplementary analgesia in the form of epidural fentanyl (Table III). There was no difference between the two groups in the quality of sensory blockade.

Hypotension $(P<0.05)$ and nausea $(P<0.05)$ were more common in the lateral position (Table IV). There was no difference in the amount of ephedrine used between the two groups.

One patient in the sitting group developed mild postspinal headache and did not require an extradural blood patch.

All babies in this study were in good condition as judged by fetal acid base status and Apgar scores. The Apgar scores were $>7$ at one minute and 9 at five minutes in all neonates.

\section{Discussion}

The results show that the time of onset of sensory analgesia to $\mathrm{T}_{4}$ and grade 3 motor blockade was faster in the lateral group $(P<0.05)$ after spinal injection of 2.0 $\mathrm{ml}$ hyperbaric bupivacaine $0.5 \%$. Furthermore, hyperbaric bupivacaine $10 \mathrm{mg}$ is an inadequate dose when injected in the sitting position: nine (39\%) parturients in the sitting group required epidural supplementation compared with only one (4\%) parturient in the lateral group $(P<0.05)$.

A possible explanation of the above findings is that injection of local anaesthetic at the $\mathrm{L}_{2-3}$ space deposits local anaesthetic at the cephalic end of the lumbar cur-
TABLE III Efficacy of sensory block during surgery

\begin{tabular}{lcc}
\hline Category & Sitting & Lateral \\
\hline A Painless & 18 & 19 \\
B Mild discomfort & 4 & 3 \\
C Moderate discomfort (supplementary & 1 & 1 \\
$\quad$ analgesia) & 1 & 0 \\
D General anaesthesia & 0 & \\
\hline
\end{tabular}

TABLE IV Incidence of complications

\begin{tabular}{llll}
\hline & Sitting & Lateral & P value \\
\hline Nausea & $5(22 \%)$ & $14(61 \%)^{*}$ & $<0.05$ \\
Hypotension & $3(13 \%)$ & $11(48 \%)^{*}$ & $<0.05$ \\
Shivering & $6(26 \%)$ & $6(26 \%)$ & NS \\
Dizziness & $4(17 \%)$ & $6(26 \%)$ & NS \\
Sleepiness & $5(22 \%)$ & $6(26 \%)$ & NS \\
Post-dural puncture headache & $1(4 \%)$ & 0 & NS \\
\hline
\end{tabular}

Values expressed as number of patients (\%).

*Significant difference between the two groups $(P<0.05)$.

vature, as the peak of the lumbar curvature is at the $\mathrm{L}_{3}$ space. If, therefore, injection is made at the $\mathrm{L}_{2-3}$ space with the parturient in the left lateral position, the hyperbaric solution will gravitate around the $\mathrm{L}_{2-3}$ space on the dependent side. When the parturient is then turned to the supine position, the local anaesthetic will have pooled mainly around the peak and the cephalic portion of the lumbar curvature. The hyperbaric solution at the peak will then move in both cephalic and caudal directions under the influence of gravity. However, there will be greater flow in the cephalic portion as the bulk of the solution will be in the cephalic portion of the lumbar curvature.

Spinal injection in the sitting position results in a hyperbaric solution passing caudally under the influence of gravity. Furthermore, once the patient is turned supine, the bulk of the solution will be on the caudal side of the lumbar curvature and the solution must first spread cephalad by bulk displacement of CSF, diffusion, or both, before gravity induces further cephalad spread. The amount of hyperbaric solution that passes caudally after spinal injection will also be dependent on the time the patient remains sitting. Therefore, it is possible that hyperbaric bupivacaine $0.5 \%$ in a dose of $2.0 \mathrm{ml}$ may provide adequate analgesia for Caesarean section when using a traditional spinal technique because the patients can be placed supine immediately after the subarachnoid injection. When using a single space needle-through-needle technique, additional time is required to thread and secure the epidural catheter. This problem may be overcome by using either a double-space technique or an "Eldor" type of epidural needle. ${ }^{9}$ 
Nine subjects in the sitting group required epidural supplementation. Although the epidural injection was given before maximum sensory analgesia as assessed by loss of cold sensation to ethyl chloride had been reached, it is possible that analgesia to $T_{4}$ may have been achieved in some of these patients if we had waited longer, as the time taken to achieve maximum blockade can take as long as 15 to $20 \mathrm{~min} .{ }^{5,8,10}$ However, we have found that if $T_{10}$ analgesia is not reached within six minutes, $T_{4}$ analgesia is very unlikely to be achieved. Previous reports have shown that $T_{10}$ analgesia with hyperbaric bupivacaine in sitting parturients occurs in $3.3^{5}$ to 5.1 min; ${ }^{10}$ and $T_{4}$ or $T_{6}$ analgesia in $8.2 \mathrm{~min}^{10}$ to $<10 \mathrm{~min}$.

Russell studied 40 pregnant women to whom he administered a subarachnoid injection of $2.0 \mathrm{ml}$ hyperbaric bupivacaine $0.5 \%$ in the right lateral position and found that the time taken to reach $T_{4}$ ranged from 7.1 to 10.2 min. ${ }^{4}$ The mean times to achieve $T_{4}$ analgesia with 12.5 $\mathrm{mg}$ hyperbaric bupivacaine injected in the lateral position ranged from $3.3-4^{11}$ to $8 \mathrm{~min}$. ${ }^{12}$

We perform combined spinal and extradural anaesthesia for both elective and emergency Caesarean section more frequently as supplementation of inadequate spinal block can be achieved via the epidural route. Furthermore, if the surgical procedure is prolonged, sensory analgesia can still be maintained by administering local anaesthetic via the epidural catheter. Regional anaesthesia for Caesarean section has a failure rate of about $4 \%$, but rates as high as $35 \%$ have been described. ${ }^{13,14}$ No patient in this study required conversion to general anaesthesia. Combined spinal and extradural anaesthesia has also been shown to provide much better intraoperative analgesia for Caesarean section than extradural anaesthesia alone. ${ }^{15}$

Patients in the lateral group had a faster onset of analgesia to $\mathrm{T}_{4}$ than those in the sitting group $(P<0.05)$. This was associated with an increased incidence of hypotension and nausea. However, there was no difference between the two groups in neonatal outcome. This is in keeping with the findings of Datta et al., Corke et al. and Kang et al. ${ }^{16-18}$ that if hypotension is promptly treated, it does not effect neonatal outcome.

In conclusion, posture does have an effect on the spread of hyperbaric bupivacaine. When using a single space needle-through-needle technique, a subarachnoid injection of $2.0 \mathrm{ml}$ hyperbaric bupivacaine $0.5 \%$ in the left lateral position provides more rapid and effective analgesia for Caesarean section than if the injection is made in the sitting position. We recommend that if induction of anaesthesia for Caesarean section is carried out in the sitting position using the single space combined spinal extradural technique then $>10 \mathrm{mg}$ hyperbaric bupivacaine should be used if rapid analgesia to $T_{4}$ is required.

\section{References}

1 Kestin IG. Spinal anaesthesia in obstetrics. $\mathrm{Br} \mathrm{J}$ Anaesth 1991; 66: 596-607.

2 Russell IF. Effect of posture during the induction of subarachnoid analgesia for Caesarean section: right v. left lateral. Br J Anaesth 1987; 59: 342-6.

3 Russell IF. Posture and isobaric subarachnoid anaesthesia Anaesthesia 1984; 39: 865-7.

4 Russell IF. Spinal anaesthesia for Caesarean section (Letter). Anaesthesia 1988; 43: 704-5.

5 Santos $A$, Pedersen $H$, Finster $M$, Endström $M$. Hyperbaric bupivacaine for spinal anesthesia in cesarean section. Anesth Analg 1984; 63: 1009-13.

6 Carrie LES, O'Sullivan G. Subarachnoid bupivacaine $0.5 \%$ for Caesarean section. Eur J Anaesthesiol 1984; 1 : 275-83.

7 Coates $M B$. Combined subarachnoid and epidural techniques (Letter). Anaesthesia 1982, 37: 89-90.

8 Bromage PR. A comparison of hydrochloride and carbon dioxide salts of lidocaine and prilocaine in epidural analgesia. Acta Anaesthesiol Scand 1965; (suppl. XVI): 55-69.

9 Eldor J, Guedj P, Gozal Y. Combined spinal-epidural anesthesia using the CSEN (Letter). Anesth Analg 1992; 74: $169-70$.

10 Lowson SM, Brown J, Wilkins CJ. Influence of the lumbar interspace chosen for injection on the spread of hyperbaric 0.5\% bupivacaine. $\mathrm{Br} \mathrm{J}$ Anaesth 1991; 66: 465-8.

11 DeSimone CA, Norris $M C$, Leighton BL, Epstein RH, Palmer $C$. Spinal anesthesia for cesarean section and post partum tubal ligation. Anesthesiology 1989; 71: A837.

12 Randalls B, Broadway JW, Browne DA, Morgan BM. A comparison of four subarachnoid solutions in a needlethrough-needle technique for elective Caesarean section. $\mathrm{Br}$ J Anaesth 1991; 66: 314-8.

13 Moir DD. Local anaesthetic techniques in obstetrics. Br J Anaesth 1986; 58: 747-59.

14 Manchikanti L, Hadley C, Markwell SJ, Colliver JA. A retrospective analysis of failed spinal anesthetic attempts in a community hospital. Anesth Analg 1987; 66: 363-6.

15 Rawal N, Schollin J, Wesström G. Epidural versus combined spinal extradural block for cesarean section. Acta Anaesthesiol Scand 1988; 32: 61-6.

16 Datta S, Alper MH, Ostheimer GW, Weiss JB. Method of ephedrine administration and nausea and hypotension during spinal anesthesia for cesarean section. Anesthesiology 1982; 56: 68-70.

17 Corke BC, Datta S, Ostheimer GW, Weiss JB, Alper MH. Spinal anaesthesia for Caesarean section. The influence of hypotension on neonatal outcome. Anaesthesia 1982; 37: 658-62.

18 Kang YG, Abouleish E, Caritis S. Prophylactic intravenous ephedrine infusion during spinal anesthesia for cesarean section. Anesth Analg 1982; 61: 839-42. 